Running head: CREATING COLLECTIVE VALUE THROUGH CO-ORDINATION

\title{
How to Do Things with Logical Expressions:
}

\section{Creating Collective Value through}

\section{Co-ordinated Reasoning}

\author{
Denis Hilton \\ University of Toulouse * \\ hilton@univ-tlse2.fr \\ Gaëlle Villejoubert \\ Leeds University Business School ** \\ g.villejoubert@lubs.leeds.ac.uk \\ Jean-Francois Bonnefon \\ University of Toulouse * \\ bonnefonduniv-tlse2.fr \\ ** Leeds University Business School \\ Maurice Keyworth Building \\ University of Leeds \\ Leeds, LS2 9JT \\ United Kingdom
}

* U.F.R. de Psychologie,

Université Toulouse-2,

5 allées Antonio Machado,

31058 Toulouse Cedex 9

France 


\begin{abstract}
We argue that logical expressions in human language enable speakers to perform particular acts as well as stating propositions which may be true or false. We present a conversational action planning model of co-ordinated reasoning, which we use to predict choice of logical expressions in situations in which two people co-operate in the face of risk and uncertainty. We first show how this model predicts preferences for formulations of conditional directives where a principal instructs an agent on how to behave in a hypothetical situation Second, we show how this model accounts for choices of quantity and probability expressions that express risk, in situations where a professional advises a client on her options. We conclude that the pragmatic signals encoded in human logical vocabulary can facilitate the co-ordination of social interaction through aiding mutual recognition of intentions on joint projects where collaboration is likely to create value.
\end{abstract}

Keywords: Logic conversation conditionals quantifiers probability 
Biographical Notes.

Denis Hilton is a professor of social psychology at the University of Toulouse, France. His research interests include social cognition, reasoning and judgment processes, and experimental economics.

Gaëlle Villejoubert is a lecturer in decision sciences in the Leeds University Business School, United Kingdom. Her research focuses on probability judgements and the communication of risks.

Jean-François Bonnefon conducts research on reasoning and decision-making at the University of Toulouse, France. His work is influenced by linguistic pragmatics and by recent formal developments in Artificial Intelligence. 


\section{How to Do Things with Logical Expressions: \\ Creating Collective Value through Co-ordination}

In 1776, the eminent economist and philosopher Adam Smith pointed out the importance of the division of labour for modern society: Without humans' capacity for specialising in tasks and collaborating with strangers, humankind would not enjoy anything near the success that it does. Somehow, without any explicit direction or centralised planning, human societies seem to be able to self-organise and re-organise into ever more successful economic and social arrangements (Seabright, 2004).Human societies thus seem to be able to make "collective minds" that maximise collective benefits for groups and enable them to prosper. How are such co-ordinated actions possible when many of the agents involved have never met in a face-to-face encounter?

As well as famously invoking the action of an "invisible hand" to regulate markets, Smith argued that this achievement depends on use of language, coupled with the human inclination to exchange goods (in Smith's words, their tendency "to truck and to barter"). Contemporary comparative psychology indeed paints a picture which is broadly in the spirit of Smith's speculation. Thus Tomasello et al. (in press) argues that humans, when compared to chimpanzees, have a tendency to enjoy sharing with others, which applies to both goods and information. Dessalles (2000) agrees that the human species has a unique disposition to give information to others - but argues that this is mainly because individuals wish to signal their worth as a coalition partner to others.

Overall and perhaps unsurprisingly, these arguments suggest that language and communication play a central role in the creation of collective value. More strikingly, 
the seemingly least bartering-laden use of language, the language of wisdom itself, plays a role in achieving the social co-ordination of intentions. In this article, we show that logical expressions such as conditionals, quantifiers and probability words serve important social functions that facilitate co-ordinated reasoning and action.

In particular, we demonstrate that logical vocabulary is impregnated with pragmatic signals - i.e. meanings that express the speaker's intentions and beliefs in the particular contexts in which they are uttered—which facilitate communication and collective planning to deal with risk and uncertainty. From this pragmatic perspective, logical vocabulary obeys a logic of goal satisfaction (cf. Kenny, 1966) which is quite different to the truth-functional criteria used to judge the correctness of a logical expression. Consider the proposition "if you see a leopard, then you run for your life". This is a logical proposition of the form "if $p$ then $q$ ". From a truth-functional perspective, this is a true statement unless there are protagonists in some implied reference group (e.g. a tribe in Kenya) who choose not to run for their life (not- $q$ ) even though they see a leopard $(p)$. Yet suppose this statement is uttered by a safari guide to inexperienced tourists in Kenya. In such a context, it is manifest that the safari guide does more than merely express a proposition that may be true or false of a given reference class of people (or animals); rather, he wants to make his listeners behave in a certain way should a certain situation arise. Such pragmatic functions are governed by social rationality, and the their quality is measured by the effectiveness with which they induce successful co-ordination through getting hearers to fulfil the speaker's intentions, e.g. by indeed running away when they have spotted a leopard.

We will illustrate our thesis with respect to empirical studies that consider two kinds of work situation requiring co-ordinated social interactions. The first study, on 
conditional instructions, examines an oft-observed case of co-ordination of activity (in work situations but also, e.g., in parent-child relationships): a principal directs an agent on how to behave as she desires in hypothetical situations. The second study, on quantifiers and probability expressions, examines situations of relationship equality, where an expert professional has to give useful advice to a client who has the ultimate power of decision. We present a conversational action planning model that predicts ways of formulating felicitous conditional instructions and advice using quantifiers and probability expressions; that is, instructions and advice which adequately communicate the intentions of the speakers and produce the appropriate effect on the listener.

\section{Co-ordinated Planning and Social Control in the Face of Risk}

Human reasoning and rationality is embedded in - and may have emerged from successful social communication. Other primates communicate and recognise intentions successfully, as when a dominant animal intimidates and inferior, and in this sense satisfy Gricean criteria for intentional communication (Grice, 1975), in that they can manifest information to others in order to get them to recognize their desires and do what the y want (Strawson, 1964). But, if both humans and primates are able to understand others as intentional agents, only humans appear to have the motivation and cognitive skills to share intentions. Whereas primates do not manifest or recognize communicative intentions, such as the providing of information that is not immediately related to any perceivable goal of the "speaker", humans, by contrast, engage in collaborative interactions where a goal is shared and actions are co-ordinated in the pursuit of this goal. Thus, humans seem to have a unique disposition to read other's intentional states, and to share information and attention in a way that close primate relatives like chimpanzees do not (Tomasello et al., in press). 
In addition, the ability of language-trained chimpanzees to understand conditional expressions has only been demonstrated in an instrumental domain, where their keeper tells them (through a visual symbol system) that if they perform a certain action they will get a reward (Premack, 1976). From the chimpanzee's point of view the conditional rule could be regarded as a kind of indication from the keeper that allows her to form a plan to obtain a reward. Consequently, we need to better understand the goaldirected functions of logical expressions (e.g. instructions, advice, promises, and threats) and their use in co-ordinating planning in order to identify both continuities and differences between humans and other primates.

If pragmatics (intentional communication) of the kind shared with other primates is first, and semantics (truth-functionality) is second, logic and probability words (e.g. If, because, some, few, possible, unlikely) may be expected to have social functions built into their everyday use, besides their truth-functional definition. Specifically, we argue that the logical vocabulary of natural language has its origins in the necessity of achieving successful co-ordination of social interactions through communication, and is very well adapted to communicating perceptions of risk, danger and opportunity. From this perspective, sentences using logic expressions can be conceived as utterances aiming to get the hearer to do things, called performative utterances, rather than as statements merely describing states of affairs, called constative statements (cf. Austin, 1962).

These performative functions of logic words may be primary. Consider the following statements:

(1) If there are few wolves in the West valley then don't hunt there.

(2) If there are a few wolves in the West valley then don't hunt there. 
The difference in meanings between (1) and (2) cannot be explained by the truth conditions of their respective antecedents: they describe similar proportions and are thus identical in this regard (Moxey \& Sanford, 1993a;b). Instead, such a difference can easily be apprehended by considering the different utilities the speaker attaches to the presence of wolves (wolves as meat, i.e., positive utility, vs. wolves as predators, i.e. negative utility). Such utilities will serve as a reason for the recommended course of action.

Rationality is defined here in terms of successful social co-ordination, which entails the correct perception and execution of the other's intentions. This definition contrasts with the verificationist criterion of being a correct description of an objective reality. Our concept of social rationality is also different to the two kinds of rationality defined by Evans and Over (1996). These authors define individual rationality either in terms of reasoning according to formal principles (e.g., Bayes' theorem) or in terms of satisfying instrumental goals. Social ratio nality is not concerned with formal principles, although socially rational judgments can overlap with formally correct judgments. Neither is social rationality to be identified with instrumental rationality, which can be quite asocial, as the fulfilling of one's instrumental goals may not need any understanding of or co-ordinating with the goals of others.

We have argued that successful social co-ordination is necessary for collectives to achieve their goals. In order to illustrate this claim, we will begin by examining the case of conditional directives whereby a principal directs an agent on how to behave in a hypothetical situation. We will then extend our analysis of conversational action planning to quantifiers and uncertainty expressions. 


\section{A Goal-based Approach to Performative Conditionals}

"If you see a leopard, run for your life." "If someone cannot show you a VIP pass, throw him out the VIP lounge." Conditional directives are performatives in that, should a hypothetical situation arise, their aim is to bring about a change in the world, a change that is desired by a principal and executed by an agent. In contrast, most work on the psychology of reasoning has examined constative conditionals (in the sense of Austin, 1962) such as indicatives and counterfactuals (see Evans \& Over, in press, for an overview), which take truth-values as more-or-less true descriptions of the world.

To this aim, we propose a simple conversational action planning (CAP) model whereby a principal (speaker) communicates his or her preferences to an agent (hearer) about what to do in a particular situation. In the language of signal detection theory, the model suggests that different formulations of the conditional relation (e.g., If event then action, If and only if event then action, If not-event then not action, Action only if event) will be used as a function of the relative costs of misses (MS: not taking the action when it is rational to do so) and false alarms (FA: taking the action when it is not rational to do so), as each conditional formulation implicitly conveys the preference of the speaker (principal).

For example, consider the following three instructions:

(3) If there is suspect baggage, then take it out and search it.

(4) [If and] Only if there is suspect baggage, then search it.

(5) If there is no suspect baggage, then do not search it.

The CAP model predicts that a principal in the position of an airport security chief whose primary concern is to stop life-threatening baggage getting though security checks, will prefer to issue the instruction (3) to airport security agents. If, 
however, his main concern is not to make passengers wait too long, he should prefer to utter (4) or (5). Results supporting this prediction are reported in Hilton, Kemmelmeier, and Bonnefon (2001).

Hilton et al. (2001) also present evidence that agents (hearers) are quite capable of inferring what they are expected to do from the conditional instruction alone, even when the context is neutral about what the desirable action to take is. For example, in one scenario participants were asked to imagine that they were shop assistants whose boss had told them either: If a customer is touching some clothes, offer him your help, If and only if a customer is touching some clothes, offer him our help, Offer a customer your help only if he is touching some clothes, and If a customer is not touching any clothes, do not offer him your help. For any given formulation, participants were asked either to suppose $\mathrm{P}$ (The customer is touching the clothes) or to suppose not-P (the customer is not touching the clothes) and indicated their understanding with regard to Q (offer help) by choosing one of the three following answers: "I must do Q", "I must not do Q", "I am free to decide what to do."

Although nothing was said explicitly in the scenario to this effect, the shop assistant may infer that her boss may either be concerned about the cost of missing the opportunity to close sales with interested customers (through not offering help when a customer is touching the clothes, avoid-MS), or the cost of false alarms which frighten customers away by being too pushy (through offering help when it is not desired, avoidFA).

Each conditional formulation appears to be informative with respect to what is required of the agent. Thus the dominant pattern elicited by if $P$ then $Q$ is that one must 
do $\mathrm{Q}$ when $\mathrm{P}$ is the case, but is free to decide what to do when $\mathrm{P}$ is not the case. Hence, this formulation succeeds in avoiding MSs, yet leaves opened the possibility of a FA. The dominant pattern elicited by if and only if $P$ then $Q$ is that one must do $Q$ when $P$ is the case, and one must not do Q when $\mathrm{P}$ is not the case. This formulation is thus interpreted in a way which prevents both MSs and FAs. The dominant pattern elicited by if notP then not $Q$ is that one is free to decide what to do when $\mathrm{P}$ is the case, but one must not do $\mathrm{Q}$ when $\mathrm{P}$ is not the case. This formulation thus prevents FAs but leaves opened the possibility of a MS. Finally, the formulation $Q$ only if $P$ elicits both patterns attached to if notP then not $Q$ and if and only if $P$ then $Q$. Thus, this formulation always prevents FAs but only sometimes prevents MSs.

These results thus showed that conditional directives can be varied to express the principal's preferences about what an agent should do should a hypothetical situation arise. We may speculate that speakers will choose one logically equivalent formulation of a causal conditional over another as a function of the speaker's goals. For example, two people may share a causal model in which serving high quality products is a recipe for customer satisfaction in restaurants. But momentary changes in context-determined utilities (e.g., in the kinds of clients that are expected that evening) may require that this shared recipe be significantly nuanced in its application: a chef instructing a buyer will say If the meat is $80 \%$ lean then buy it when he is most concerned with the attaining a desirable goal (serving excellent food in a restaurant), but say If the meat is $20 \%$ fat then don't buy it when most concerned with the costs of a mistake (serving substandard food in a restaurant). So even though both conditionals have the same truth-values, we argue that they will have different performative functions because they express different preferences. 
Note that it would be anomalous to express the principal's preferences probabilistically, for example by saying If the customer is touching clothes, then probably offer him your help. It is the principal's responsibility and not the agent's to assume the risk that the instruction may backfire. On the other hand, it seems that the principal could readily use probabilistic qualifications with constative conditionals in these kinds of situation: for example, the statement If the customer is touching clothes, then he would probably like your help does not sound anomalous. Intuitively, where the boss accepts that it is the assistant's right to decide what to do in this case (and take responsibility for the outcome), such a formulation could readily be used as a piece of indirect advice. More generally, it seems to us that probabilistic advice can be appropriately given when the speaker wishes to help the hearer make the correct decision, but does not want to impose a solution directly. Be low, we turn to consideration of a study of how the conversational action planning model can be applied to advice using quantifiers and probability expressions.

\section{Advice on What to Do Under Uncertainty: Pragmatic Functions of Quantifiers and Probability Words}

Everyday experts and novices alike use words and phrases to characterize quantities and uncertainty. A reservation clerk may tell his clients that few seats are left on the plane they wish to take or alternatively that there are a few seats left; a doctor may tell his patients that recovery is highly likely or alternatively, that it is not certain that they will recover. What will determine the professional adviser's choice of word? What inferences may the recipient of the advice draw on the basis of this choice?

Research aiming at understanding how people select and understand quantifiers was based on the assumption that they denote vague numerical quantities (Hakel, 1969; 
Pepper \& Prytulak, 1974) and that probability phrases denote vague numerical probabilities (Beyth-Marom, 1982; Lichtenstein \& Newman, 1967), often formalised as membership functions (Wallsten, Budescu, Rapoport, Zwick, \& Forsyth, 1986).

Leaving aside general problems with the membership function approach (Weber \& Hilton, 1990), we concentrate our attention here on what might lead a speaker to select one word over another which denotes the same vague quantity.

\section{Advice-giving and the Choice of Quantity and Uncertainty phrases}

Consider a scenario (Villejoubert and Hilton, 2004) in which a travel agent wishes to help her client take the best decision about whether to book a ticket quickly (with the risk of taking a less-than-ideal flight) or to take his time about his decision (with the risk of booking too late to get a seat). Depending on the experimental condition, the clerk disposes of two pieces of information that can influence her choice of quantifier; the knowledge that there are 15 or 45 seats left on a 120-seat plane, and that these seats will normally be sold out in 2 or 14 days. The airlines scenario represents a particular case of the general decisional context presented in Figure 1.

Here, the action consists in buying the plane tickets straight away and the status quo consists in delaying the purchase. If the tickets are bought straight away, the probability $p_{1}$ of success is 1 (i.e., there is no longer a risk of losing the seats and $p_{2}=$ 0 ), the outcome corresponds to the tickets bought, which bears utility $u_{1}$. If the purchase is delayed, the customer may or may not be able to buy tickets and has to bear the costs of a miss. In case of a correct rejection, the delay of the purchase is followed by the possibility of buying tickets, with the probability $p_{3}$ where $0=p_{3}<1$. The tickets bought at a later time have utility $u_{3}$ and $u_{3}>u_{1}$ (i.e., the adviser knows that the customer prefers to delay his purchase). But, in the case of a miss, the delay of the 
purchase may also be followed by the impossibility of buying the tickets, with a probability $p_{4}$ where $0=p_{4}<1$, and no associated utility $(\mathrm{u} 4=0)$. Figure 2 summarizes this context.

An experiment was conducted in which participants were presented with a choice between two pieces of advice. The first piece of advice was a warning against the consequences of the status quo: "Be careful, it is possible that you won't have time to make a decision because there are ... seats available." The second piece of advice encouraged the client to delay his decision: "Don't worry, you have time to make your decision because there are ... seats available." Results showed that the time left to decide (14 days vs. 2 days) had a strong effect on a measure of the perceived risk that the seats would be sold out. In line with this, it was found that when clients had 14 days to decide, the number of seats left influenced the polarity of the quantifier word chosen. When there were 45 seats left, participants were more likely to use positive polarity words to encourage their clients to take their time because there were a few, quite a few, or many seats left. However, when clients had only 2 days to decide, participants almost exclusively used negative polarity words and warned them to decide quickly because there were few, very few, or not many seats left, regardless of whether the actual number was 15 or 45 . In our view, these results illustrate our thesis that quantifiers in these situations are principally selected on the basis of their pragmatic function (encouraging vs. discouraging a putative course of action) rather than in terms of how well they describe some objectively given quantity.

These results were replicated with a more complex scenario involving a doctor advising his patient on whether or not to undertake a surgical operation. Participants were about three and a half times as likely to choose a negative probability phrase when 
the miss outcome (i.e., the negative consequence following the absence of action) was more severe than the false-alarm outcome (i.e., the negative consequence following the action). These results provide substantial support for our claim that the choice of polarity words is driven by the perceived utility of the action outcome, and that this utility is itself determined by comparison to the utility of the status quo, which serves as a reference point.

\section{Receiving Advice: Felicity and Emotional Response}

The preceding results concerned the analysis of the speaker's use of quantifiers and probability words. The CAP model, however, also has implications for the understanding of the hearer's interpretations of these words. Consider once more the example of the airlines clerk who warns her client that he should make his booking sooner rather than later because they are $f e w$ seats left on the plane he wishes to take. From a semantic perspective, one would merely expect that the client would assign a vague quantity to the number of seats left based on his personal membership function for the quantifier "a few". By contrast, we characterised good advice as a successful coordination between the speaker and the hearer. From this perspective, we can also assume that a given piece of advice will give rise to specific non-numerical expectations from the hearer. Thus, in the airlines example, the client should draw specific implicatures about the context within which this advice is taking place.

We hypothesized that the extent to which such expectations are later fulfilled should in turn affect the client's degree of satisfaction and emotional response both to the outcome of his decision and to the clerk's advice. Thus, if the advice is felicitous (i.e., if it recommends the best action to satisfy the hearer's goal in a given context), hearers should feel happier and more satisfied, independently of the type of the decision 
outcome (i.e., correct rejection or hit). Conversely, non- felicitous pieces of advice should entail lesser degrees of happiness and satisfaction as they will lead to either a miss or a false alarm outcome.

Another experiment was conducted in order to test these predictions. The experiment again used the airlines and surgeon scenarios, but this time participants had to take the role of the recipient of the advice. Half the participants were told the clerk indicated there were few seats left. They were then asked to imagine that they bought the plane ticket straight away and realised two days later that there were no seats left (i.e., that the advice was felicitous) or that there were still seats left (i.e., that the advice was not felicitous). The other half were told that the clerk indicated there were $a$ few seats left on the plane and were asked to imagine that they subsequently delayed the purchase of their ticket. Here again the felicity of this advice was manipulated by telling participants either that there were seats available two days later (felicitous advice) or that there were not (infelicitous advice).

The estimated proportions of seats left on the plane were independent of the quantifier used in the advice. However, as in the previous experiment, the perceived risk of losing a seat was significantly higher when participants were told that they were "few seats" left (as opposed to "a few seats"). All participants were then asked to indicate their emotional state and their satisfaction following the realisation that there were (or not) seats available two days later. Results showed that people felt happiest, most satisfied, and least regretful when the advice was felicitous, independently of the actual advice (i.e., encouraged or warned against delay). Participants felt significantly less happy, less satisfied, and more regretful when they were encouraged to buy without delay but were then told that there were still tickets available two days later. However, 
they were least happy, least satisfied, and most regretful when they were encouraged to delay their purchase only to realise that there were no seats left two days later. Felicity of the advice also determined their emotions towards the reservation clerk. They felt happy towards the clerk as long as her advice was felicitous (independently of whether he advised to act or to delay action). Conversely, participants felt significantly less happy towards the clerk when her advice was not felicitous.

These results thus provide additional support for the social rationality hypothesis. Namely, when choosing to frame her advice with a positive or negative quantifier, the speaker is eliciting certain expectations in the recipient of this advice. The successful fulfilment of these expectations leads to goal satisfaction and in turn mediates the recipient's degree of happiness, satisfaction and his perceived regret as well as his emotional response to his advisor.

\section{Conclusion}

Many would point to the unique human mastery of logic and mathematics as a major explanation of the success of the species. But without wishing to minimise the importance of the representational power of abstract symbolic systems for human engineering and computer science, we believe that logical vocabulary has pragmatic functions that make it essential to co-operation and planning in the face of uncertainty. The prevalence of these pragmatic nuances, and their nuisance value for those who wish to use these words to signify abstract logical and mathematical operations, suggests to us that natural human reasoning emerges from these kinds of co-operative interactions.

The encouragement/discouragement perspective we have presented for conditional instructions and advice using quantifiers and probability expressions is quite general. For example, it could predict patterns of conditional advice : When the costs of 
misses are high we predict advice of the kind: If you have this operation you should preserve your sight whereas if the costs of false alarms are high we predict advice of the kind If you don't have this operation you may lose your sight. Observation of such patterns of response will show equivalence between ways of expressing uncertainty and conditionals: They are fundamentally causal arguments for or against a course of action, and their expressed strength and direction reside in the degree to which the speaker wishes to encourage or discourage the action in question.

We have introduced a specific kind of instrumental rationality - that of successful co-ordination of social interactions. We have argued that for intersubjective conditionals a rational choice of a conditional formulation from the speaker's perspective will normally be one that promotes her interests by getting the hearer to understand what she wants. For a hearer, a rational interpretation will normally be one that best represents the speaker's intention (whether the hearer decides to do as the speaker wishes or not). Rationality comes to be defined here in terms of successful social co-ordination, and justified in terms of collective benefits (cf. Sperber, 2001).

Recognizing the social rationality of conditionals allows a new perspective to be taken on their development and adaptive functions. It seems that performative conditional directives of the kind that we have studied emerge early in social interaction between caregivers and children (Luria, 1959). Children may in turn internalise external speech (Vygotsky, 1962) and appropriate it to regulate their own activity (Luria \& la Yudovich, 1956). This perspective would seem to support Sperber's (2001) argument that: "It is generally taken for granted that the logical and inferential vocabulary is - and presumably emerged - as tools for reflection and reasoning. From an evolutionary point of view, this is not particularly plausible. The hypothesis that they emerged as tools of 
persuasion may be easier to defend."

Although evolutionary psychologists find it implausible that the human mind would have evolved some domain-general reasoning ability (e.g. Cosmides, 1989; Gigerenzer and Hug, 1992), it does seem to us that one plausible evolved general ability would be conversational skills that as speakers are needed to get others to see the point, and as hearers are needed to see what the speaker wishes them to do and to do it. Indeed, if these skills are integrated with general goalbased planning and reasoning strategies, then it would not be surprising that people reason especially well about propositions when they can see the point of them.

Indeed, there is no doubt that, although there are many social animals, humans are among the most social. Many characteristics of the human mind may thus have evolved to facilitate social interaction and cooperation, for such interactions and cooperation enhanced the survival prospects of early humans. Hence, the capacity for logic may have emerged as a social phenomenon long before it became a scientific one. While truth-values may not constitute the building bricks for the human mind, the value of shared viewpoints does seem to provide the cement for building collective minds. 


\section{References}

Austin, J. L. (1962). How to do things with words. Oxford: Clarendon Press.

Beyth-Marom, R. (1982). How probable is probable: A numerical translation of verbal probability expressions. Journal of Forecasting, 1, 257-269.

Cosmides, L. (1989). The logic of social exchange: has natural selection shaped how we reason? Studies with the Wason selection task. Cognition, 31, 187-276.

Dessalles, J-L. (2000) Aux origines de la parole: Une histoire naturelle de la parole. Paris-Hermes.

Evans, J. St. B. T., \& Over, D.E. (1996). Rationality and reasoning. Hove: Psychology Press.

Evans, J. St. B. \& Over, D.E. (in press). If. Oxford: Oxford University Press.

Gigerenzer, G., \& Hug, K. (1992). Domain specific reasoning, social contracts, and perspective change. Cognition, 43, 127-171.

Grice, H.P. (1975). Logic and conversation. In P. Cole \& J.L. Morgan (Eds.): Syntax and Semantic 3: Speech Acts (pp. 41-58). New York: Academic Press.

Hakel, M. D. (1969). How often is often? American Psychologist, 23, 27-44.

Hilton, D.J., Bonnefon, J-F \& Kemmelmeier, M. (2001). Pragmatics at work: Formulation and interpretation of conditional instructions. In J.D. Moore, \& K. Stenning (Eds), Proceedings of the 23rd Annual Conference of the Cognitive Scie nce Society, Edinburgh, Scotland, August 1-4. Hillsdale: Lawrence Erlbaum.

Kenny, A. (1966). Practical inference. Analysis, 26, 65-75.

Lichtenstein, \& Newman, 1967

Luria, A.R. (1959). The directive function of speech in development and dissolution, part I. Word, 15, 341-352. 
Luria, A.R., \& la Yudovich, F. I. (1956). Speech and the development of mental processes in the child. Harmondsworth: Penguin.

Moxey, L. M., \& Sanford, A. J. (1993a). Communicating quantities: A psychological perspective. Hove, UK: Lawrence Erlbaum Associates.

Moxey, L. M., \& Sanford, A. J. (1993b). Prior expectation and the interpretation of natural language quantifiers. European Journal of Cognitive Psychology, 5, 7391.

Pepper, S., \& Prytulak, L. S. (1974). Sometimes frequently means seldom: Context effects in the interpretations of quantitative expressions. Journal of Research in Personality, 8, 95-101.

Premack, D. (1976). Intelligence in ape and man. Hillsdale, NJ: Lawrence Erlbaum Associates.

Seabright, P. (2004). The company of strangers: A natural history of economic life. Princeton: Princeton University Press.

Smith, A. (1776/1991). An inquiry into the nature and causes of the wealth of nations New York: Prometheus Books.

Sperber, D. (2001). An evolutionary perspective on testimony and argumentation Philosophical Topics, 29, 401-413.

Strawson, P.F. (1964). Intention and convention in speech acts. Philosophical Review, $73,439-60$.

Tomasello, M., Carpenter, M., Call, J., Behne, T. \& Moll, H. (in press). Understanding and sharing intentions: The origins of cultural cognition. Behavioral and Brain Sciences. 
Villejoubert, G. and Hilton, D. (2004). The pragmatics of quantifiers. Paper presented at Conference on Thinking, Leuven, July 2004.

Vygotsky, L.S. (1962). Thought and Language. Cambridge: MIT Press.

Wallsten, T. S. Budescu, D. V., Rapoport, A., Zwick, R., \& Forsyth, B. (1986). Measuring the vague meanings of probability terms. Journal of Experimental Psychology: General, 115, 348-365.

Weber, E.U., \& Hilton, D.J. (1990). Contextual effects in the interpretation of probability words: Perceived base-rate and severity of events. Journal of Experimental Psychology: Human Perception and Performance, 16, 781-789. 


\section{Figure Captions}

Figure 1. Formal representation of the decision to act.

Figure 2. Formal representation of the Airlines scenario context. 
FIGURE 1

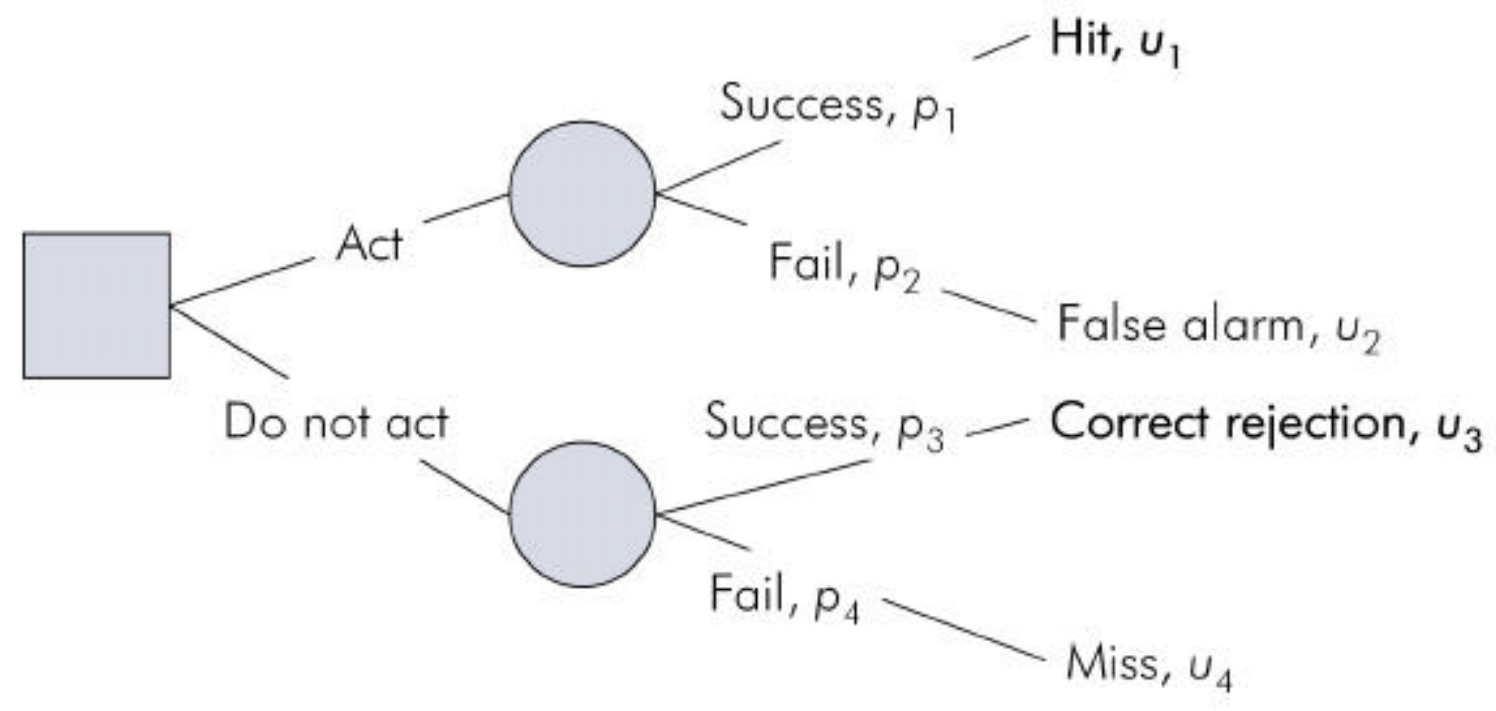


FIGURE 2

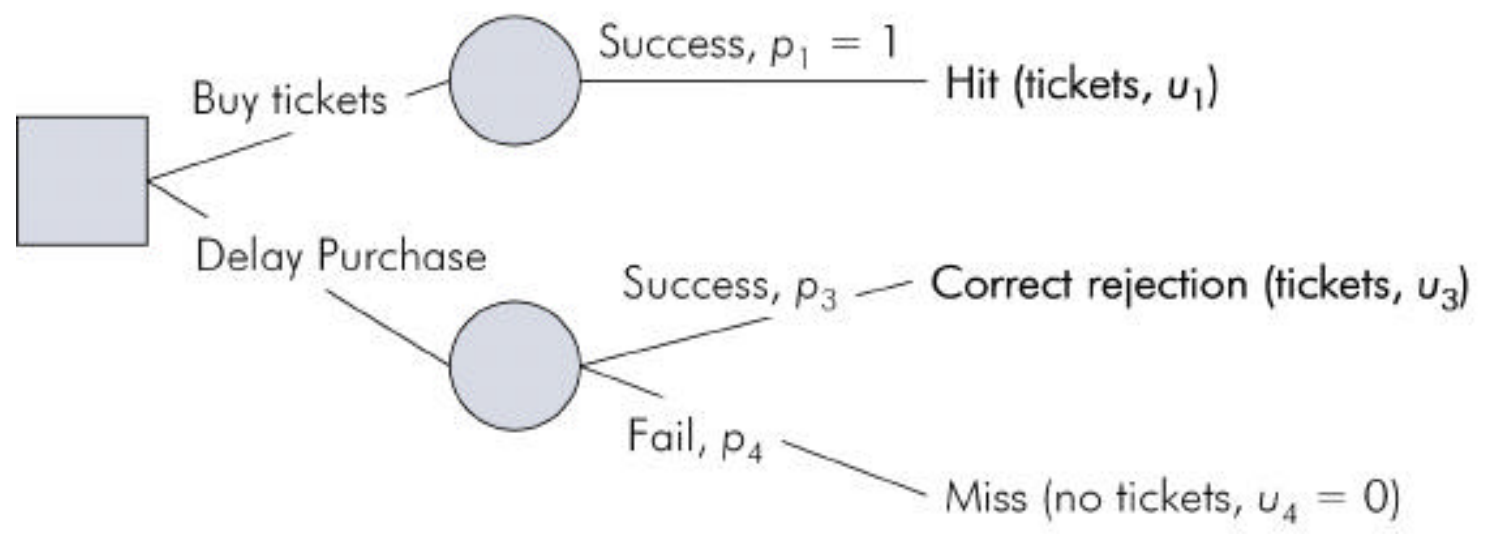

